УДК 628.31

\title{
Е.Н. СЕРПОКРЫДОВ
}

аспирант кафедры водоснабжения и водоотведения

Ростовский государственный строительный университет

\section{ДИНАМИКА ИЗМЕНЕНИЙ МАССООБМЕННЫХ ХАРАКТЕРИСТИК КЕРАМИЧЕСКИХ АЭРАТОРОВ «БАКОР» В ТЕЧЕНИЕ ГОДА ЭКСПДУАТАЦИИ}

\author{
OVERVIEW OF CHANGES IN MASS EXCHANGE CHARACTERISTICS \\ OF BAKOR CERAMIC AERATORS OVER 12 MONTHS OF SERVICE
}

Изучены массообменные характеристики аәраторов «Бакор» в течение 12 месяцев эксплуатациии в промышленных условиях в системах аэрациии при очистке сточных вод: городских, шахтных, убойного цехха птицекомбината. Установлено изменение массообменных характеристик на +/- (5-7) \% в течение года. Дань рекомендации по применению аәраторов $в$ практике проектирования и эксплуатации при очистке сточных вод.

Ключевье слова: аәраторы "Бакор», массообменные характеристики, системы аэрации, сточные воды, городские, шахтные, убойный изех птицекомбината, сохранение первоначальных характеристик, промышиленные условия эксплуатацчии.

Практически важным является изучение массообменных характеристик аэраторов в процессе их длительной эксплуатации. Керамические аэраторы “Бакор” были установлены в промышленные очистные сооружения: городских сточных вод (Ростовская станция аэрации, РСА), шахтных (шахта им. Кирова, Ростовская обл.), бройлерной фабрики (г. Благодарный, Ставропольский край). Наблюдения за характером изменения показателей массообмена аэраторов проводили в течение от 3 до 12 мес.

На РСА аэраторы установили в 5 технологических точках сооружений (по 3 аэратора в каждой): в преаэраторе первичного отстойника, в канале возвратного активного ила, в регенераторе аэротенка, в биореакторе доочистки, в контактном резервуаре. На очистных сооружениях шахты им. Кирова аэраторы разместили в зоне аэрации горизонтального отстойника. На локальных очистных сооружениях ООО “Ставропольский бройлер" аэраторы “Бакор" были размещены в аэрируемом усреднителе сточных вод с мешалками.
This article presents the results of studying the mass exchange characteristics of Bakor aerators during the 12-month industrial application of this aerators in aeration systems designed for the treatment of waste waters originating from different sources: cities, mines, and slaughterhouses of poultry processing plants. The study revelead $a+/-(5-7) \%$ change of the mass exchange characteristics over the course of a year. The article also gives recommendations on using the aerators in the design and application of waste water processing facilities.

Key words: bakor aerators, mass exchange characteristics, aeration systems, waste waters, city waters, mine waters, slaughterhouses of poultry processing plants, industrial application.

В течение года периодически через 1,5-3 месяца аэраторы извлекали из очистных сооружений и в лабораторных условиях определяли массообменные характеристики, после чего их устанавдивали обратно, а на последующий контроль брали другой образец.

Опытно-промышленная эксплуатация аэраторов “Бакор" на РСА осуществлялась в режимах, одновременно моделирующих возможные варианты аэрации: 1 - работает непрерывно в течение суток; 2 - подача воздуха откдючается на 5 - 6 часов с сохранением остаточного давления воздуха в подводящем к аэратору шланге; 3 - также отключение на 5-6 часов, но подводящий шланг отсоединяди от воздуховода, чтобы на аэратор воздействовало тодько гидростатическое давление столба жидкости.

Данные режимы нужны были для проверки вдияния на кольматаж пор и внутренних подводящих каналов воздуха в аэраторах при плановом или внезапном отключении электроэнергии. Это позволяло по массообменным характеристикам 
определить тип (поверхностное и/или внутреннее) загрязнения аэраторов и, соответственно, при необходимости предложить режимы регенерации.

На примере аэраторов, извлеченных из коридора регенератора аэротенка, можно видеть (рис. 1), что кинетические кривые окисления сульфита и растворения свободного кислорода в жидкости практически идентичны при постоянном режиме аэрации (без перерыва регенератор Б) и при периодическом (с перерывом регенератор С). Из этого следует, что воздухоподводящая система в силу конструктивных особенностей аэраторов “Бакор" не требует стояков для выпуска водовоздушной смеси. Потери напора, определенные в лабораторных условиях после извлечения аэраторов, для всех точек их размещения составили 0,1-0,2 м водяного столба.

Аналогичным образом (табл. 1 и 2) были определены массообменные характеристики аэраторов через 4, 6, 8, 10 и 12 месяцев эксплуатации. При этом установили, что определение показателей необходимо вести в мокрых аэраторах, не допуская их высыхания. В противном случае наблюдается кольматаж пор и показатели массообмена снижаются на 60-70 \%.

Можно видеть, что за 10 (табл. 1) и 12 (табл. 2) месяцев опытно-промышленной эксплуатации уменьшение массообменных характеристик аэраторов по сравнению с новым не превысило 15 \% для разных технологических условий размещения. Большие уменьшения их характерны для аэраторов из контактного резервуара. Проверка факела аэрации показала увеличенный размер пузырьков воздуха, т. е. из мелкопузырчатой наблюдался среднепузырчатый режим аэрации. Это можно объяснить увеличением диаметра пор в аэраторе вследствие химического взаимодействия гипохлорит - ионов с вещественным составом аэратора.

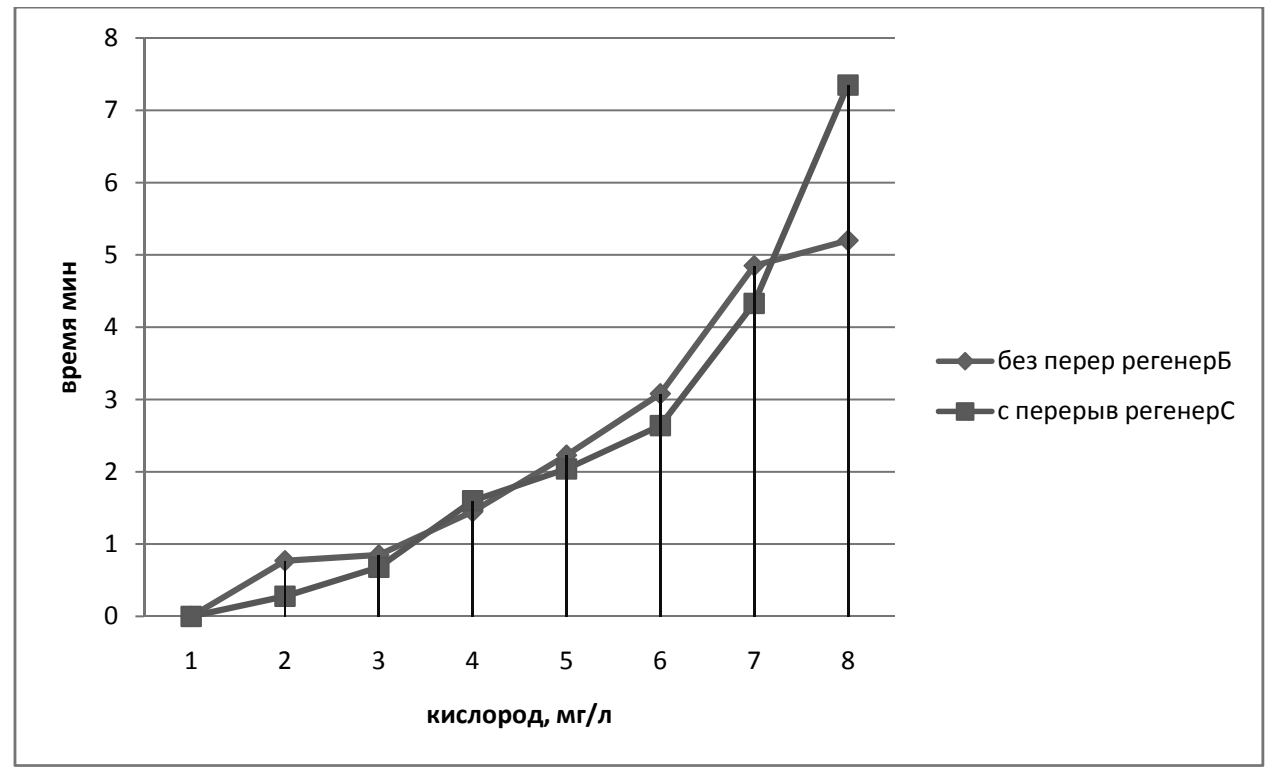

Рис. 1. Кинетика насыщения жидкости кислородом аэратором «Бакор-1450» из регенератора при прерывистом (регенер С) и непрерывном (регенер Б) режиме аэрации (расход воздуха 3,9 м³/ч)

Массообменные характеристики («Бакор - 750»), 10 месяцев эксплуатации (расход воздуха 3,9 м³/ч)

\begin{tabular}{|c|c|c|c|c|}
\hline Место установки аэратора & $\mathrm{k}_{\mathrm{VT}}, \mathrm{u}-1$ & КПД, \% & $\begin{array}{c}\text { Окислительная способность, } \\
\qquad \mathrm{\kappa г} / \mathrm{\Psi} \cdot \mathrm{M}^{3}\end{array}$ & $\begin{array}{c}\text { Эффективность аэрации, } \\
\mathrm{krO}_{2} /\left(\mathrm{KB}^{\prime} \cdot ч\right)\end{array}$ \\
\hline Биореактор доочистки & 10,34 & 6,1 & 3,87 & 7,23 \\
\hline Доток возвратного ила & 11,27 & 5,3 & 4,16 & 8,0 \\
\hline Регенератор & 11,48 & 5,9 & 3,70 & 7,11 \\
\hline Контактный резервуар & 11,41 & 4,8 & 3,42 & 6,41 \\
\hline Новый аэратор & 11,9 & 5,54 & 4,48 & 8,2 \\
\hline
\end{tabular}


Массообменные характеристики («Бакор-750»), 12 месяцев эксплуатации

\begin{tabular}{|c|c|c|c|c|}
\hline \multirow{2}{*}{$\begin{array}{l}\text { Место расположения оборудования, } \\
\text { режим работы, расход воздуха, } \text { м³ }^{3} \text {. }\end{array}$} & \multicolumn{4}{|c|}{ Параметрические показатели при высоте слоя воды 0.40 м } \\
\hline & $\mathrm{k}_{\mathrm{VT}}, \mathrm{u}-1$ & КПД, \% & $\begin{array}{c}\text { окислительная способность, } \\
\text { Кг } / \mathrm{\Psi} \cdot \mathrm{M}^{3}\end{array}$ & $\begin{array}{c}\text { эффективность аэрации, } \\
\mathrm{KrO}_{2} /\left(\mathrm{kBT}^{\prime} \cdot \mathrm{q}\right)\end{array}$ \\
\hline $\begin{array}{l}\text { Лоток возвратного ила; } \\
\text { непрерывно; } 1,8\end{array}$ & 7,5 & 14,6 & 3,64 & 6,15 \\
\hline Биореактор; непрерывно; 1,8 & 10,7 & 28,5 & 3,65 & 6,84 \\
\hline Регенератор; непрерывно; 3,9 & 8,15 & 14,30 & 4,94 & 9,1 \\
\hline $\begin{array}{l}3 \text { мес. хранения под открытым небом } \\
+9 \text { мес. работы в конт-м рез-ре; } 3,9\end{array}$ & 7,44 & 2,95 & 0,97 & 1,82 \\
\hline Контактный рез-р; непрерывно; 3,9 & 6,4 & 2,93 & 0,96 & 1,79 \\
\hline Rehau; преаэратор; 3,9 & 8,35 & 4,67 & 2,38 & 5,46 \\
\hline
\end{tabular}

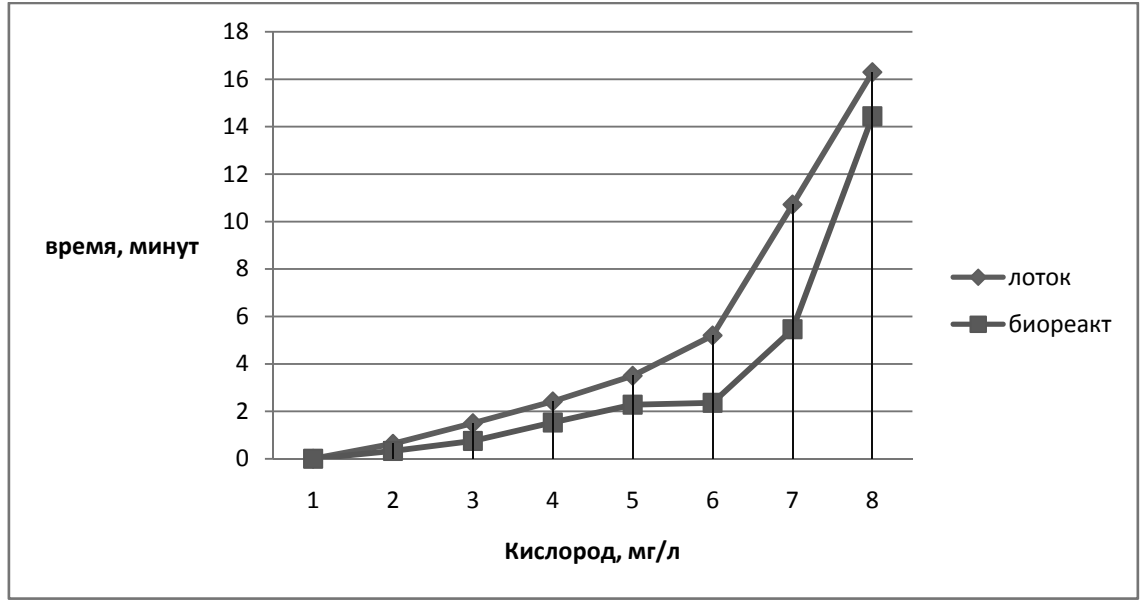

Рис. 2. Кинетика окисления сульфита и растворения кислорода аэраторами из дотка возвратного ила и биореактора

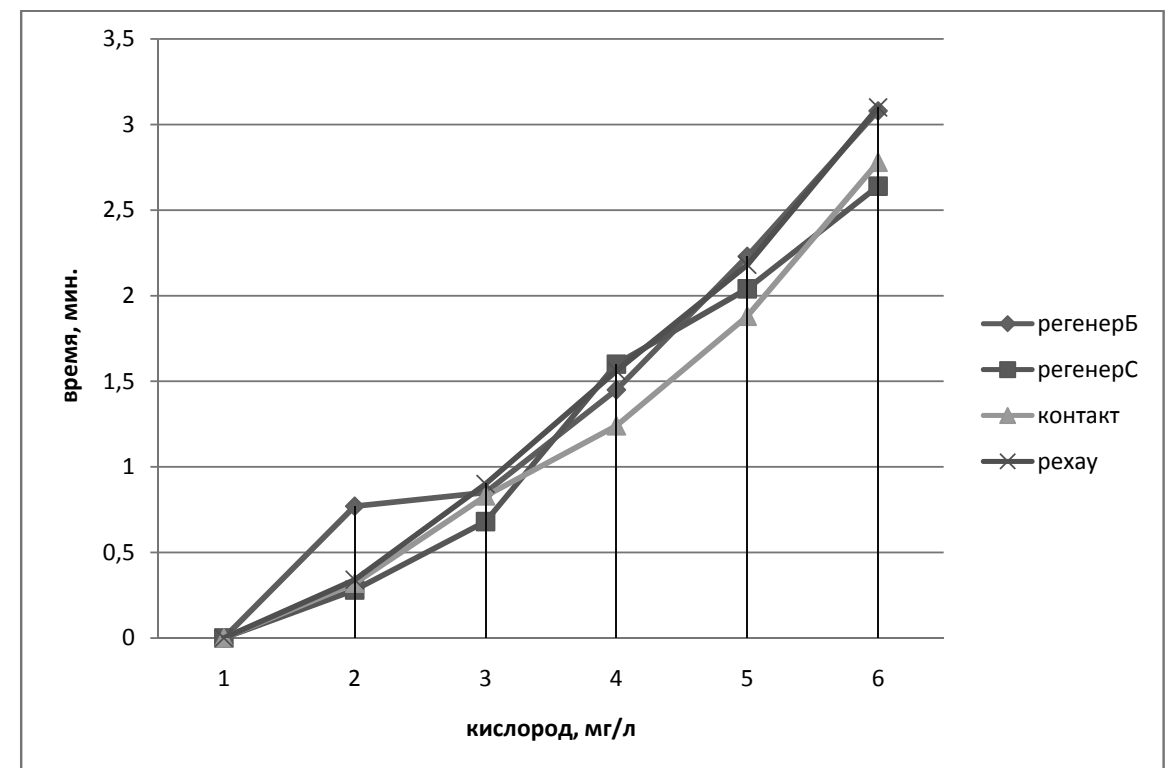

Рис. 3. Кинетика окисления сульфита и растворения кислорода аэраторами из регенератора без отключения от воздухораспредительной системы (регенер Б), с отключением (регенер Б), из контактного резервуара, из преаэратора 
Показатели массообмена до и после 4 месяцев очистки шахтных вод

\begin{tabular}{|c|c|c|c|c|c|c|c|c|}
\hline \multirow{3}{*}{ Аэратор } & \multicolumn{8}{|c|}{$\begin{array}{c}\text { Параметрические показатели аэратора при расходе воздуха 3,9 и 7,8 м³/ч } \\
\text { и высоте слоя воды 0,45 м через } 4 \text { месяца эксплуатации }\end{array}$} \\
\hline & \multicolumn{2}{|c|}{$\mathrm{k}_{\mathrm{VT}}, \mathrm{u}-1$} & \multicolumn{2}{|c|}{ КПД, \% } & \multicolumn{2}{|c|}{$\begin{array}{c}\text { окислительная } \\
\text { способность, кг } / \mathbf{\Psi} \cdot \mathrm{M}^{3}\end{array}$} & \multicolumn{2}{|c|}{$\begin{array}{c}\text { эффективность аэрации, } \\
\mathrm{KrO}_{2} /(\text { кВт·ч) }\end{array}$} \\
\hline & 3,9 & 7,8 & 3,9 & 7,8 & 3,9 & 7,8 & 3,9 & 7,8 \\
\hline 1400 (исходный) & 8,94 & 14,95 & 7,3 & 2,47 & 1,55 & 2,65 & 2,92 & 4,97 \\
\hline 1400 (после 4 мес. эксплуат.) & $\frac{6.42}{10.67}$ & 14,36 & $\frac{11.1}{17.4}$ & 2,13 & $\frac{2.50}{4.31}$ & 2,02 & $\frac{4.67}{7.2}$ & 3,79 \\
\hline
\end{tabular}

Примечания:

1 - ввиду повышенной температуры воды $\left(25,3^{\circ} \mathrm{C}\right)$ насыщение кислородом воздуха проводиди до 6 мг $\mathrm{O}_{2} / \lambda$;

2 - в числителе приведены параметрические показатели после регенерации аэратора струей водопроводной воды, в знаменателе - после механической очистки щеткой и промывки водой.

Сравнительная оценка кинетики по методике переменного дефицита кислорода (рис. 2) для разных условий эксплуатации показала сохранение высоких массообменных характеристик через 12 месяцев эксплуатации для аэраторов из разных мест расположения.

Через 12 месяцев эксплуатации на РСА практически не изменились характеристики аэраторов, установленных в регенераторе аэротенка и в лотке возвратного активного ила. Уменьшились показатеди массообмена в аэраторах в биореакторе доочистки и контактном резервуаре. После струйной и механической регенерации показатели массообмена в аэраторе биореактора доочистки практически восстановились до первоначальных значений.

Общепринятый по зарубежной терминологии $\alpha$-фактор характеризует отношение массопереноса кислорода в чистой воде и иловой смеси, для аэраторов «Бакор» получено значение $\alpha$-фактор 0,273 , что коррелируется по величине с показателями современных аэраторов [4].

Установленная экспериментально стабильность биохимического окисления органических и неорганических загрязнений в аэротенке с аэраторами «Бакор» дает основания для проверки собственно окислительной технологии, например, в очистке шахтных вод, содержащих до 100 мг/л железа [2], что характерно для водоотливов угледобывающих предприятий Ростовской обл.

Для проверки этого положения во второй из четырех линий очистных сооружений шахты им. Кирова (Красносулинский район) в камере окисления смонтированы 5 аэраторов с манометрами и счетчиками газа. Аэраторы обеспечивали равномерное насыщение вод кислородом до 8,5 мг/л (по кислородомеру). Аэраторы через 1,5-2 месяца извлекали из сооружений и определяли параметры массообмена.

На поверхности аэратора наблюдалась «шуба» из гидроксидов железа [3] толщиной 3-5 мм, которая после высыхания придала новый цвет поверхности, однако в «мокром» состоянии наблюдалась преимущественно мелкопузырчатая аэрация и отсутствие видимой кольматации пор. В то же время снижение массообменных характеристик составило около $30 \%$ (табл. 3).

После предварительной промывки поверхности аэратора водой под напором снижение первоначальных показателей массообмена не превысило 20 \%, что, в первом приближении, свидетельствует о возможности такого типа регенерации поверхности аэраторов. Данная тенденция сохранилась и после четырех месяцев эксплуатации (табл.3).

Установлена устойчивая эффективность окисления железа (II) в (III) в зоне аэрации при очистке шахтных вод (не менее 90 \%). Также установлено, что вследствие оседания гидроксидов железа (III) и карбонатов кальция и магния на поверхность через 12 месяцев эксплуатации требуется механо-химическая или термохимическая регенерация аэраторов.

На локальных очистных сооружениях бройлерной фабрики (г. Благодарный, Ставропольский край) в усреднителе дополнительно к имеющимся мешалкам была смонтирована система аэрации с аэраторами «Бакор». Наблюдения в течение 6 меся- 
цев показали эффективность окисления сульфидов и сероводорода, что повысило в целом надежность работы очистных сооружений.

Исходя из полученных в производственных условиях в течение 3-12 месяцев эксплуатации данных о массообмене, энергетических затратах, технических решений по размещению, можно предложить варианты технологического использования аэраторов «Бакор» в процессах очистки сточных вод: 1 - реконструкция аэротенков; 2 - увеличение окислительной способности действующих аэротенков путем установки аэраторов без их остановки и опорожнения; 3 - установка аэраторов в сочетании с мешалками; 4 - разработка и модификация режима работы аэротенков в SBR - реакторы; 5 - для сокращения числа подкдючений отдельными трубами установка секционных аэраторов (с применением или без применения грузоподъёмного оборудования); 6 - подбор воздуходувного оборудования ведется на потери напора 0,1-0,2 м водяного столба в аэраторах.

Таким образом, стабильность массообменных показателей аэраторов «Бакор» в течение 12 месяцев эксплуатации при очистке сточных вод в промышленных условиях указывает на необходимость их расширенного внедрения в технодогии очистки вод.

\section{БИБЛИОГРАФИЧЕСКИЙ СПИСОК}

1. Мешенгиссер, Ю.М. Теоретическое обоснование и разработка новых полимерных аэраторов для биологической очистки сточных вод: автореф. дис. ... д-ра техн. наук [Текст] / Ю.М. Мешенгиссер.- М.: ФГУП «НИИ ВОДГЕО», 2005.

2. Серпокрылов, Е.Н. Аэраторы из пористой проницаемой керамики НТЦ «Бакор» - характеристики и перспективы применения [Текст] / Е.Н. Серпокрылов, Е.Н. Фесенко, М.Н. Саенко, Н.С. Серпокрылов, И.А. Куиик, А.Б. Красный, В.П. Тарасовский, А.С. Маджитов// ВиК. - 2012. - № 1-2. - С. 73-81.

3. Баженов, В.И. Инженерное оформдение крупныхаэротенков по экономичному принципу [Текст] / В.И. Баженов // Водоочистка. Водоподготовка. Водоснабжение. - 2008. - №1. - С. 16-18.

4. Ingenieria de aguas residuales: tratamiento, vertido i reutilizacion [Text]. - Mexico: Metcalf \& Eddy, 1996. - 1485 p.

(C) Серпокрылов Е.Н., 2013 